\title{
The Effects of Chemical Purification on the Color of Thin and Thick Juices in Sugar Beet Factories
}

\author{
Maryam Arajshirvani ${ }^{1}$, Mohammad Hojjatoleslami* ${ }^{1}$ \\ 1- Food Sciences Department, Islamic Azad University, Shahrekord Branch, Iran.
}

\section{A B S T R A C T}

Background and Objectives: Recognizing the impurities of sugar beet and also comparing different methods of juice purification have shown that the chemical purification based on lime and carbon dioxide is really efficient and economic in the sugar industry. Factories have to control and improve purification stages to achieve clear juice with high chemical purity, low color, minimum hardness, sufficient thermal resistance and with no insoluble solid matters in producing white sugar with high purity and efficiency. The aim of this study was to investigate the effects of alkalinity changes in preliming and liming stages on improving the color of thin and thick juices.

Materials and Methods: In the current study, changes in pre-liming alkalinity (0.2, 0.3 and 0.9) and liming alkalinity $(1.3,1.4,1.5$ and 1.6) $(\mathrm{mg} \mathrm{CaO} / 100 \mathrm{ml}$ juice) during the operation were studied in Sharekrod sugar factory. According to the discharge and retention time of each stage (raw juice, thin juice, and thick juice), the samples were taken and the color changes were studied.

Results: The results showed that alkalinity changes of 0.4 in preliming along 1.4 in liming and 0.4 in preliming along 1.3 in liming (mg CaO/ $100 \mathrm{ml}$ juice) caused imbalance of cation/anion, sucrose hydrolysis and invert sugar, and produced undesired color in the thin or thick juice. These changes also had undesired effects on the juice's resistance. But 0.2 in preliming and 1.6 in liming as well as 0.3 in pre-liming and 1.6 in liming had positive effects. Therefore, a thin juice with $\mathrm{pH}$ of 8.9 and low color increase $(20 \%)$ was produced.

Conclusions: According to the results, some of the enforced changes were more effective in purification process and improved it.

Keywords: Preliming, Liming, Chemical purification, Sugar beet juice

\section{Introduction}

One of the most important steps in sugar factories is the raw beet juice purification stage. This step causes suitable thin juice production; thereupon, production of thick juice after concentration occurs. This phase of the process is known as the heart of the sugar factory. Purification problems can negate the good performance of other parts, resulting in nondesirable yield $(1,2)$. Purification through physical and chemical treatment methods can improve or enhance the purity of a compound (1).

Juice purification term is used in sugar industry to improve and increase the purity of the extracted juice
$(1,3)$. Purification is started technically after juice extraction $(1,4)$. The purification goal is to separate non-sugar matters using different methods such as sedimentation by decantation or filtration (3). The final product is a high purity juice with no colloids and low color or hardness $(1,3)$. It must be considered that successful purification depends on previous stages such as:

1- sugar beet quality

2- quality of harvesting, especially beet topping

3- ventilation status of silo

4- $\mathrm{pH}$ of washing water (alkaline or neutral) 
5- status of liquid extraction process $(2,5)$.

Juice color is very important in sugar production processes. Obtained juices from beet processes are yellow or brown, which are finally converted into white sugar (5).

Colorful compounds are polymers with different molecular weights, structures and properties. Reactions between amino acids and carbohydrates, $\mathrm{pH}$ changes and thermal effect of sugar production steps cause formation of colorful polymers These impurities may enter the sugar crystals and cause negative effects on the quality and/or the quantity of white sugar. Therefore, the color is one of the most important problems of sugar processes (5).

Many parameters affect the color of sugar liquid. Studies have shown that sugar color is mainly produced from the alkaline analysis of invert sugars and construction of melanoidins while the color of sugar beet itself is mainly related to the herbal color pigments. Some color pigments also exist, which pass all the processes and enter the product (6); however, as it was mentioned, sugar analysis is the main source of colorful compounds. Monosaccharides, especially glucose and fructose have been known as the main contributing compounds in color formation. Heating monosaccharides under acidic or basic conditions cause destructive reactions and intermediate compounds. The polymerization of these compounds make colors (7).

Glucose and fructose are produced from sucrose hydrolysis. Obtained colorful compounds of sucrose are enzymatic colorful compounds such as melanin or non-enzymatic compounds such as melanoidins, alkaline analysis of hexoses products (HADPs) and caramels. Melanins are deposited in the sugar purification process; so these combinations are not technological problems (7).

Amino compounds exist in the sugar beet extract, and maillard reaction occurs in the presence of monosaccharides and their carbonyl compounds followed by browning. Maillard has a complicated chemical reaction including a set of consecutive and parallel reactions (7). Melanoidins are polymerization results of non-saturated carbonyl compounds from Maillard's reaction with amines. Melanoidins are probably made of repeated units of Schiff base. However, melanoidin is also considered as a polymer of furan and pyrrole. This construction consists of ether bonds and reductase systems (7).The ratio and amount of Maillard's reaction depend on various situations such as temperature, heating time, $\mathrm{pH}$, water amount and the nature of reactors. The ratio and amount of Maillard reaction increase by $\mathrm{pH}$ increment. The optimum $\mathrm{pH}$ is 6-8. At $\mathrm{pHs}$ less than 3 and higher than 9, other non-enzymatic reactions may compete with Maillard reaction.

Browning ratio increases by temperature (8). An increase about $10{ }^{\circ} \mathrm{C}$ will increase the reaction rate by two to three times. The ratio of formed melanoidins increases by the heating time. The ratio of Maillard's reaction also depends on the available water. The maximum browning occurs in $80-90 \%$ brix (8).

Glucose and fructose have the highest amounts in sugar beet. They show different chemical reactions with the amino acids of sugar liquid under different conditions. According to the studies, fructose is more reactive in weak alkaline environments. Amino acids, which contribute in reaction with this monosaccharide, are $\gamma$-amino butyric acid, lysine> aspartic acid, proline, phenyl alanine>leucine, glutamic acid, glycine>alanine and valine, which are general amino acids found in sugar beet extract (9).

Aspartic acid and glutamic acid are produced from asparagine and glutamines. Amino butyric acid is a highly reactive compound in browning reactions that can be formed in beet juices from the degradation reactions of glutamine conversion products, e.g. pyrrolidone carboxylic acid, via 2-pyrrolidone. The concentration of amino butyric acid in thick juices may be two times higher than that found in the corresponding raw juice (10).

Products of alkaline analysis of hexoses and melanoidins cause $80 \%$ of the extract's color. Monosaccharides in the alkaline aquatic environment of HADPs (hexose alkaline degradation products) are placed under adverse or reversible reactions (10).

Although classical purification of raw juice is an efficient-economical method used in many factories of the world such as Iran, few studies are extant about improving the alkalinity of liming stage and its effects on sugar production's efficiency. This study was carried out to investigate the effects of alkalinity changes in preliming and liming stages on improving the color of thin and thick juices.

\section{Materials and Methods}

The effects of changes in preliming alkalinity and liming alkalinity on reducing the color amount of juice were investigated in the current study. 
Lime to raw juice in chemical purification is classically carried out in two stages. Three alkalinity levels (including $0.2,0.3$, and $0.4 \mathrm{mg} \mathrm{CaO} / 100 \mathrm{ml}$ juice) were enforced. Researches show that the most important goal of liming in this stage is neutralizing the acidic $\mathrm{pH}$ of raw juice and reaching the optimum $\mathrm{pH}$ for coagulation and sticking colloidal impurities, especially proteins (5).

Then four levels of alkalinity were enforced in the main liming stage including $1.3,1.4,1.5$ and $1.6 \mathrm{mg}$ $\mathrm{CaO} / 100 \mathrm{ml}$ juice.

According to the output and retention time, the samples were taken in each stage from the input raw, thin and thick juices in three replications. The study was carried out in Shahrekord Sugar Company during the plant operation in 2015. Changes in preliming stage was called factor $\mathrm{A}$, and in liming stage factor B. Treatments are presented in Table1.

Preparing samples: The samples were poured in glass containers with lids and frozen at $-20^{\circ} \mathrm{C}$. They were analyzed later in the Chemistry Laboratory.

Measurement of the thin juice color: According to Icomsa recommendations, $420 \mathrm{~nm}$ (blue) and $560 \mathrm{~nm}$ (green) are internationally accepted lengths $(1,11)$.

The color was measured using spectrophotometry (S2100, Unico, USA) at $420 \mathrm{~nm}$. After filtering the thin juices, their light reduction was compared with the control (distilled water) at $420 \mathrm{~nm}$, and the color was calculated according to Icomsa unit as follows: $\mathrm{FIE}=(\mathrm{E} 420 \times 100) /(\mathrm{Bx} . \mathrm{dL})$

$\mathrm{F}_{\mathrm{IE}}$ : juice color according to Icomesa unit
E420: reduction in the light intensity of juice at the wavelength of $420 \mathrm{~nm}$

Bx: dry matter of juice (\%)

D: density of thin juice at $20{ }^{\circ} \mathrm{C}$

L: the length of measurement cell $(\mathrm{cm})$

Measurement of the thick juice color: Previous method was also used for thick juice. At first, the sample was diluted with a certain amount of water and its Brix was determined. Then the color was measured and the previous equation was used for the diluted sample (1).

\section{Results}

The effects of different levels of alkalinity preliming and liming on the color of thin juice: Variance analysis results (Table 2) showed the significant effect of factor A $(\mathrm{p}<0.05)$. Mean comparison results (Figure 1) revealed that $0.4 \mathrm{mg}$ $(\mathrm{CaO} / 100 \mathrm{ml})$ had the highest, and $0.2 \mathrm{mg}(\mathrm{CaO} / 100$ $\mathrm{ml}$ ) had the lowest colors. The increasing alkalinity showed the more amounts of color in this stage. Factor B also affected this trait significantly and $1.5 \mathrm{mg}(\mathrm{CaO} / 100 \mathrm{ml})$ had the highest effect $(\mathrm{p}<0.05)$. The least color amount was obtained in $1.3 \mathrm{mg}$ $(\mathrm{CaO} / 100 \mathrm{ml})$ and $1.6 \mathrm{mg}(\mathrm{CaO} / 100 \mathrm{ml})$ (Figure2).

Interaction of factors had significant effect on the color of thin juice $(\mathrm{p}<0.05)$; the highest color amounts was obtained by $4-15$ treatment $(0.4$ preliming along 1.5 liming). The least color amount was produced by treatment 3-13, which was due to the low invert amounts of raw juice (Figure3).

Table 1. Naming of treatments

\begin{tabular}{lccc}
\hline Treatments & New names & $\begin{array}{c}\text { Alkalinity in liming } \\
(\mathrm{mg} \mathrm{CaO} / 100)\end{array}$ & $\begin{array}{c}\text { Alkalinity in preliming } \\
(\mathrm{mg} \mathrm{CaO} / 100)\end{array}$ \\
\hline $0.2-1.3$ & $2-13$ & 1.3 & 0.2 \\
$0.2-1.4$ & $2-14$ & 1.4 & 0.2 \\
$0.2-1.5$ & $2-15$ & 1.5 & 0.2 \\
$0.2-1.6$ & $2-16$ & 1.6 & 0.2 \\
$0.3-1.3$ & $3-13$ & 1.3 & 0.3 \\
$0.3-1.4$ & $3-14$ & 1.4 & 0.3 \\
$0.3-1.5$ & $3-15$ & 1.5 & 0.3 \\
$0.3-1.6$ & $3-16$ & 1.6 & 0.3 \\
$0.4-1.3$ & $4-13$ & 1.3 & 0.4 \\
$0.4-1.4$ & $4-14$ & 1.4 & 0.4 \\
$0.4-1.5$ & $4-15$ & 1.5 & 0.4 \\
$0.4-1.6$ & $4-16$ & 1.6 & 0.4 \\
\hline
\end{tabular}


Table 2. Variance analysis results of experimental treatments

\begin{tabular}{lcccc}
\hline \multirow{2}{*}{ Source of Variation } & \multirow{2}{*}{ Degrees of freedom } & \multicolumn{3}{c}{ Mean squares } \\
\cline { 3 - 5 } & 2 & Thin juice & Thick juice & Color changes \\
\hline Preliming alkalinity & 3 & $161311^{*}$ & $950806^{*}$ & $366^{*}$ \\
Liming alkalinity & 6 & $155968^{*}$ & $922917^{*}$ & $1947^{*}$ \\
Preliming alkalinityx Liming alkalinity & 24 & $107767^{*}$ & $171818^{*}$ & $676^{*}$ \\
Error & 35 & 560 & 464 & 8 \\
Total & -- & -- & -- & - \\
CV & & & 0.88 & 4.2 \\
\hline$*$ is significant at 5\% probability level. & & &
\end{tabular}

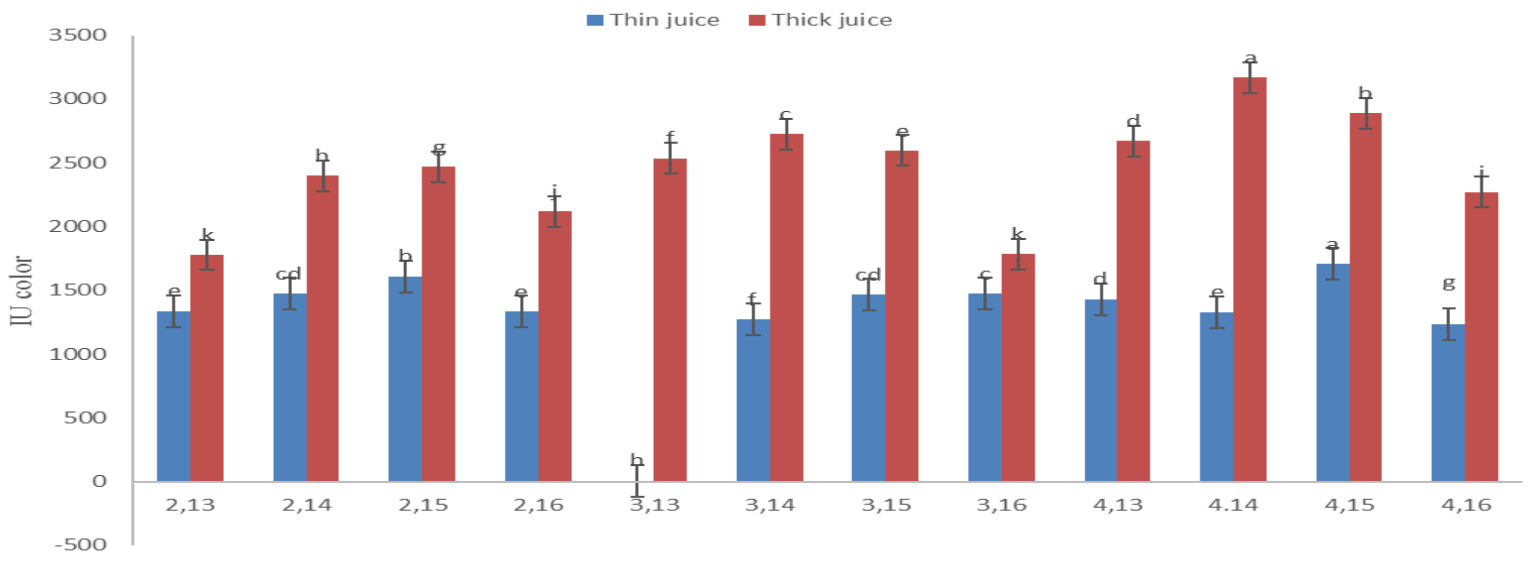

Alkalinity preliming and liming

Figure 3. Color of thin juice and thick juice at various interaction levels

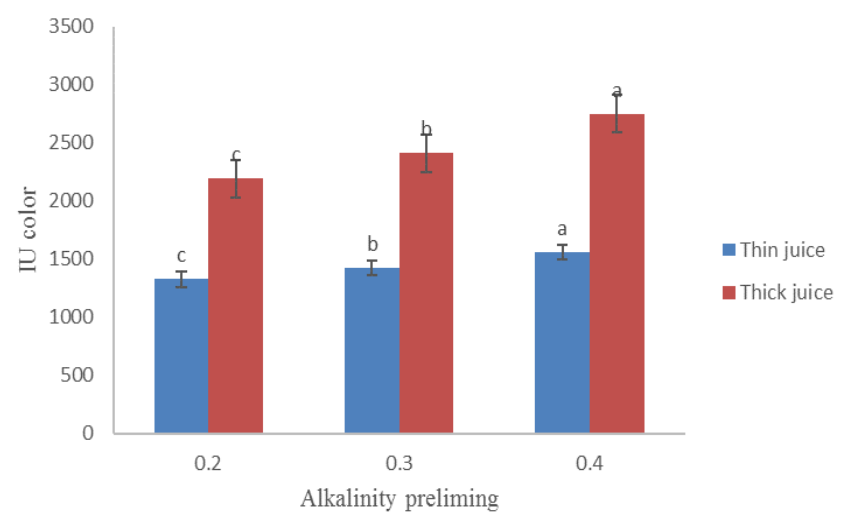

Figure 1. Effect of preliming alkalinity on thin juice and thick juice color

The effects of different levels of alkalinity preliming and liming on the color of thick juice: The thick juice color was affected significantly by factor $\mathrm{A}(\mathrm{p}<0.05)$, and the deepest color belonged to $0.4 \mathrm{mg}(\mathrm{CaO} / 10 \mathrm{ml})$. Higher alkalinity levels increased the color value (Figure 1).

Factor $\mathrm{B}$ affected the thick juice color and the colorful ones. $1.4 \mathrm{mg}(\mathrm{CaO} / 100 \mathrm{ml})$ had the most colorful juices whereas $1.6 \mathrm{mg}(\mathrm{CaO} / 100 \mathrm{ml})$ had the least (Figure 2).

Interaction of the factors also affected the color. Treatment 4-14 had the highest effect whereas

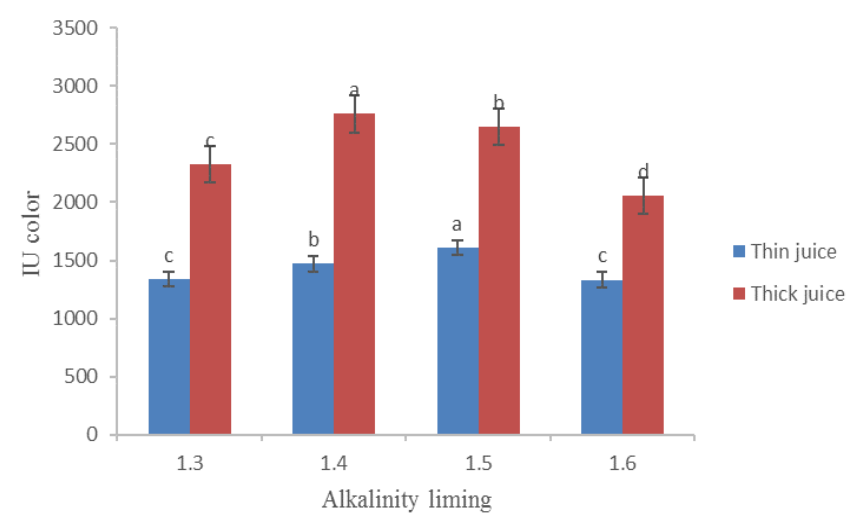

Figure 2. Effect of liming alkalinity on thin juice and thick juice color

treatments 2-13 and 3-16 had the least effects (Figure 3).

Interactive effects of the factors on color changes from thin to thick juice: Interaction effect of the factors showed that treatments 2-16 and 3-16 had the least color changes from thin to thick juice while these treatments were the best treatments for thick juice. Treatments 3-14, 4-13 and 4-14 showed high color intensity. These treatments produced also high color intensity in the thick juice. Color changes' percentage is presented in Figure 4. 


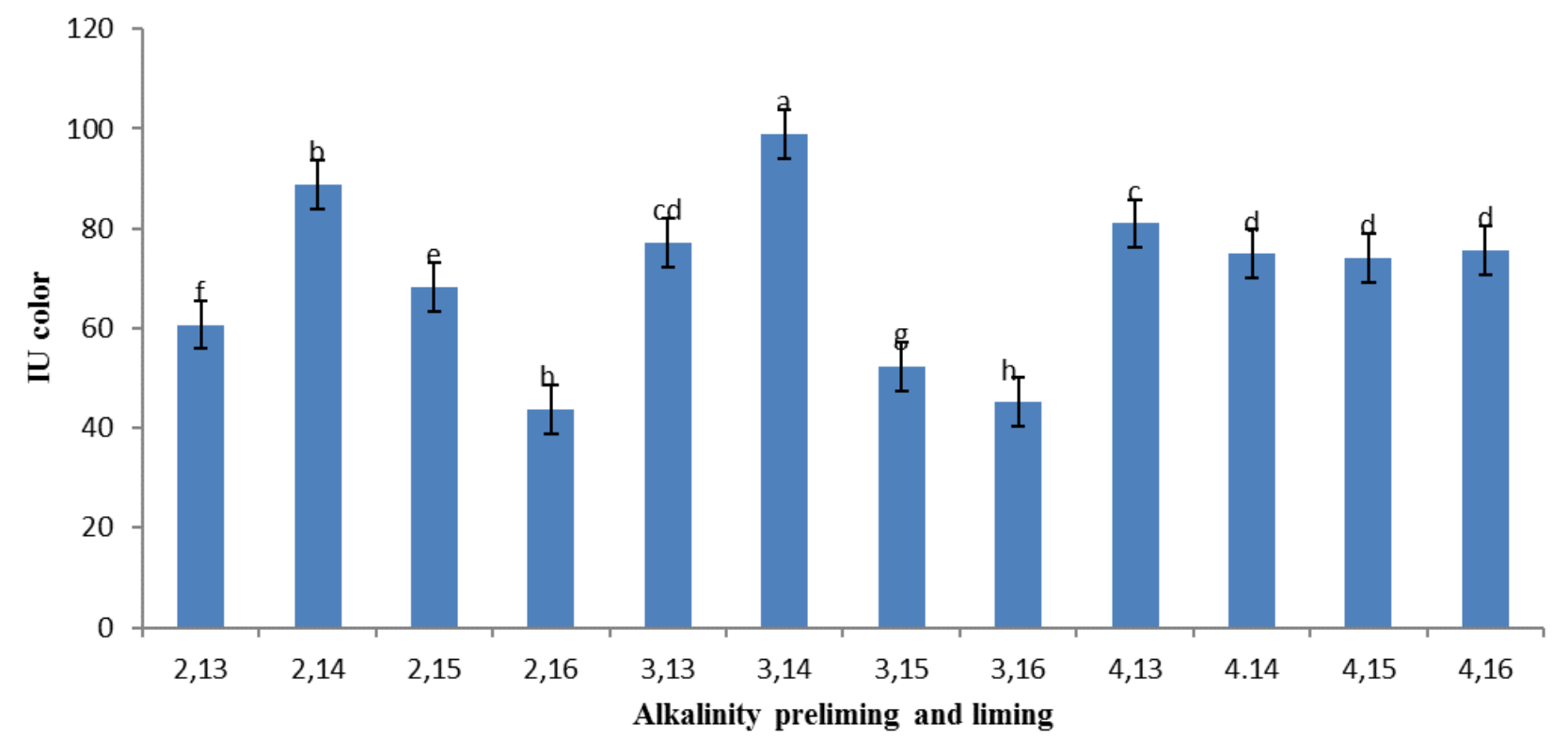

Figure 4. Color change percentage from thin juice to thick juice

\section{Discussion}

The effects of different levels of preliming alkalinity on the color of thin juice can be a reason for the existence of high invert amounts in the input juice. High alkalinity also caused alkaline degradation of sucrose. Therefore, higher invert amounts, which produce more color alkalinity (12). Different thin juice colors are due to invert amounts of raw juice and different levels of liming alkalinity which is used to obtain optimum alkalinity for sucrose hydrolysis (13). Interaction of different levels of preliming and liming alkalinity on the color of the thin juice was probably the reason for the existence of high invert amounts of raw juice and so high alkalinity, which cause alkaline degradation of sucrose. Furthermore, the alkalinity had probably been at the levels, which prevented sucrose hydrolysis. It is better to say that the invert amounts of raw juice should be studied more.

The results showed that the color of thin juice depends on the invert amounts of raw juice as well as on the color of the first carbonation juice. The color of the first carbonation juice depends on the degradation of the invert sugar of raw juice whenever liming and carbonation are appropriate. So the main color producing factor is invert amount, which is in agreement with others $(5,13$ and 14). Studies have shown that color formation in the production processes of sugar beet is mainly because of the alkaline hydrolysis of invert sugar as well as the melanoidin production (10). Our results confirm this point. Treatments such as 4-15 or 2-15 had considerable invert amounts apart from the effects of purification condition.

The results of different levels of preliming and liming alkalinity on the color of the thick juice showed that higher color intensity in the treatments such as 4-14 can be the result of more invert sugar in the related thin juice. The existence of these sugars (fructose and glucose) in condensation phase and exposure to high temperatures lead to color formation. Sucrose hydrolysis occurring in condensation stage produces sugars and increases the intensity of the thick juice's color (14).

These results are in agreement with the previous reports announcing that high temperature and long retention time in the operators plus low stability of thin juice against heat (because of alkalinity) are the most important reasons of sucrose hydrolysis in the operators, which, finally, increase the color of thick juice $(6,14)$.

Interactive effects of the factors on color changes from thin to thick juices showed that production of color compounds in this process is mainly due to sugar analysis reactions and monosaccharides, especially glucose and fructose, which are the most important intermediate compounds in color formation. Heating these sugars under basic or acidic conditions leads to the reactions and compounds, which have participated in colorful polymers production $(10,14)$. 
This is in agreement with the results of many previous studies, reporting that fructose and glucose are produced from sucrose hydrolysis along the production processes $(15,14)$. Obtained colorful compounds of sucrose are enzymatic colorful compounds such as melanin, non-enzymatic compounds such as melanoidins, products of alkaline analysis of hexoses (HADPs) and caramels. Melanins are deposited in the sugar purification process; so these combinations are not technological problems, rather others, especially the enzymatic colors cause problems $(15,16)$. The current study results showed the different effects of alkalinity levels on removing the color producing factors. Furthermore, the existence of amino compounds in sugar beet extract is not sufficient for producing melanoidins unless monosaccharides and carbonyl compounds are produced. If the process situation causes increased monosaccharides, the colorful compounds will be increased. Fructose and glucose have the highest amounts of monosaccharides in the process of sugar beet $(15,17)$. The amounts of colors in the treatments were studied in the juices to have a better explanation for the produced colors.

\section{Conclusion}

According to the results, some of the enforced changes were more effective in the purification process and improved it. McGinnis defined the chemical purification as producing the juices with high quality sugar and minimal waste of sugar in molasses (5).

In this study, alkalinity affected the purification process, and the color amount was reduced considerably in some treatments. This effect was obvious in treatments 2-16 (0.2 preliming -1.6 liming $\mathrm{mg} \mathrm{CaO} / 100 \mathrm{ml}$ juice) and 3-16 (0.3 preliming-1.6 liming $\mathrm{mg} \mathrm{CaO} / 100 \mathrm{ml}$ juice) in which the color intensity was reduced in their thin juice. Thick juice of these treatments also had low color. It means that alkalinity can increase the thermal resistance of the thin juice so it can be safe against color changing reactions in the condensation stage.

According to the research results, changing alkalinity in preliming and liming stages has considerable effects on the whole purification stages or, better say, on the produced thin juice, and finally, on the purity of produced sugar. Controlling the alkalinity in these stages leads to better removal of impurities, and affects the amount of invert sugar, especially the color of the carbonated juice.

Many other parameters also affect the purification process that controlling them can improve the purification up to $80-90 \%$. As chemical purification is still the most economical method, more studies about controlling the conditions of different parts of the chemical purification are proposed.

It is to be mentioned that the purity of filtrated juice depends on the total amount of non-sugars in the raw juice. Therefore, the most important pre-filtration conditions, which must be controlled, are:

1. avoiding prolonged storage in silos and good ventilation in short term storing

2. separating the beets storage from different regions

3. paying due attention to washing situation, grass and gravel separators and transferring canals related to the infection load

4. controlling the extraction stage; its $\mathrm{pH}$ and water must be controlled completely.

The effect of alkalinity (preliming and liming) on invert sugar, onion and cation content of thin and thick juices is the aim of our future study.

\section{Acknowledgement}

\section{Financial disclosure}

The authors declared no financial interest.

\section{Funding/Support}

This work was financially supported by the Islamic Azad University, Shahrekord Branch, Iran.

\section{References}

1. Asadi M. Beet-sugar hand book. New York: John Wiley \& Sons Inc 2007.

2. Chauhan M, Kumar V, Chaudhary S, et al. Life cycle assessment of sugar industry A review. Renewable and Sustainable Energy Review 2011; 15(7): 3445-3453.

3. Draycott AP. Sugar Beet. 3ed. Oxford: Blackwell Publishing Ltd 2006.

4. Forsyth DJ. Appropriate Technology in Sugar Manufacturing. World Development 1977; 5(3): 189202.

5. McGinnis RA. Beet Sugar Development Foundation Technolog. 3rd ed. Colorado: Fort Collins 1982 .

6. Bento LSM. Study of colour formation during Carbonatation in Cane Sugar Refining using GPC and ELS detector, Proc. A.V.H. Conf 1999; 23-27.

7. Martins SIFS, Jongen WMF, Van Boekel MAJS. A review of Maillard reaction in food and implications to kinetic 
modeling. Trends in Food Science and Technology 2001; 11: 364-373.

8. Yaylayan VA. Classification of the Maillard reaction: A conceptual approach. Trends in Food Science and Technology. 1997; 8: 13-18.

9. Shore M. Broughton NW, Dutton JV, et al. Factors affecting white sugar colour. Sugar Technology Reviews. 1984; 12: 1-99.

10. Coca M, García M, et al. Study of coloured components formed in sugar beet processing. Food Chemistry. 2004; 86(3): 421-433.

11. ICUMSA Method Book . 1994. Barten's Pub., Berlin.

12. Fujimaki M, Namiki M, Katō H. Amino-Carbonyl Reaction in Food and Biological Systems. Elsevier. 1986.
13. Jianmei Yu, Chung C, Saska M. The Behavior of Invert Sugar in Sugar Processing. Technical Proceedings of the Sugar Industry Technologists. 2011.

14. Vanderpoel PW, Schiweck HM, Schwartz TK. Sugar Technology Beet and Cane Sugar Manufacture. 8th ed. Barten's Pub., Berlin. 1998.

15. Salehi F. Current and future applications for nanofiltration technology in the food processing. Food and Bioproducts Processing. 2013; 20-23.

16. Danehy JP. Mailardreactions:Nonenzymatic browning in food systems with special reference to the development of flavors. Adv.Food Res. 1986; 30: 77-138.

17. Coca M, García M. Mato S, et al. Evolution of colorants in sugar beet juices during decolorization using styrenic resins. Journal of Food Engineering. 2008; 89(4): 429434. 